Sven Klimpel · Sonja Rückert

\title{
Life cycle strategy of Hysterothylacium aduncum to become the most abundant anisakid fish nematode in the North Sea
}

Published online: 9 September 2005

(C) Springer-Verlag 2005

\section{Parasitol Res (2005) 97:141-149}

Due to typesetting errors, Tables 1 and 2 were published incorrectly in the PDF and the print version of this article. The correct version is given here.

The online version of the original article can be found at http:// dx.doi.org/10.1007/s00436-005-1407-6

\section{S. Klimpel $(\bowtie) \cdot$ S. Rückert}

Institute of Zoomorphology, Cell Biology and Parasitology,

Heinrich-Heine-University Düsseldorf, Universitätsstraße 1,

40225 Düsseldorf, Germany

E-mail: Sven.Klimpel@uni-duesseldorf.de

Tel.: + 49-211-8113402

Fax: +49-211-8114499

S. Rückert

Center for Tropical Marine Ecology,

Fahrenheitstr. 6, 28359 Bremen, Germany 
Table 1 Haddock (M. aeglefinus). Stomach content and parasitation with H. aduncum at different stations

\begin{tabular}{|c|c|c|c|c|c|c|c|c|c|c|c|c|c|c|c|}
\hline $\begin{array}{l}\text { Station } \\
\text { Prey item/group }\end{array}$ & \multicolumn{5}{|l|}{1} & \multicolumn{5}{|l|}{2} & \multicolumn{5}{|l|}{3} \\
\hline $\begin{array}{l}\text { Foraminifera, } \\
\text { benthic }\end{array}$ & & & & & & & & & & & 0.01 & 2.63 & 0.24 & 0.01 & 0.66 \\
\hline Polychaeta & 2.69 & 37.93 & 2.65 & 7.87 & 399.02 & 0.67 & 50.00 & 19.35 & 26.46 & 2290.50 & 0.64 & 42.11 & 13.27 & 15.85 & 1226.24 \\
\hline Oligochaeta & & & & & & & & & & & 0.07 & 10.53 & 1.42 & 0.21 & 17.16 \\
\hline $\begin{array}{l}\text { Copepoda, } \\
\text { Calanoida }\end{array}$ & 1.90 & 48.28 & 1.87 & 0.25 & 102.35 & & & & & & 0.14 & 21.05 & 2.84 & 0.06 & 61.05 \\
\hline Decapoda & 2.31 & 41.38 & 2.27 & 1.90 & 172.55 & 0.11 & 12.50 & 3.23 & 0.71 & 49.25 & 0.02 & 5.26 & 0.47 & 0.39 & 4.52 \\
\hline $\begin{array}{l}\text { Euphausiacea } \\
\text { Isopoda }\end{array}$ & & & & & & & & & & & 0.02 & 2.63 & 0.47 & 0.37 & 2.21 \\
\hline Mysidacea & & & & & & & & & & & & & & & \\
\hline Bivalvia & 0.31 & 10.34 & 0.31 & 0.88 & 12.30 & 0.11 & 12.50 & 3.23 & 1.06 & 53.63 & 0.13 & 26.32 & 2.61 & 7.04 & 253.99 \\
\hline Sipunculida & & & & & & & & & & & & & & & \\
\hline $\begin{array}{l}\text { Sagitta sp. } \\
\text { Bryozoa }\end{array}$ & & & & & & & & & & & 0.01 & 2.63 & 0.24 & 0.02 & 0.68 \\
\hline Asteroida & 0.10 & 10.34 & 0.10 & 0.52 & 6.41 & 0.11 & 12.50 & 3.23 & 2.29 & 69.00 & 0.06 & 13.16 & 1.18 & 0.89 & 27.24 \\
\hline Echinoida & & & & & & & & & & & & & & & \\
\hline Ophiuroida & 15.07 & 48.28 & 14.83 & 26.35 & 1988.17 & 1.44 & 75.00 & 41.94 & 51.32 & 6994.50 & 2.69 & 47.37 & 55.45 & 49.62 & 4977.17 \\
\hline $\begin{array}{l}\text { Ascidiacea } \\
\text { Ammodytes sp. }\end{array}$ & & & & & & & & & & & 0.02 & 5.26 & 0.47 & 7.46 & 41.71 \\
\hline $\begin{array}{l}\text { Hippoglossoides } \\
\text { platessoides }\end{array}$ & & & & & & & & & & & 0.01 & 2.63 & 0.24 & 0.59 & 2.18 \\
\hline Parasite & A & $\mathrm{P} \%$ & I & $\mathrm{mI}$ & stage & A & $\mathrm{P} \%$ & I & $\mathrm{mI}$ & stage & A & $\mathrm{P} \%$ & I & $\mathrm{mI}$ & stage \\
\hline H. aduncum & 18.31 & 100.0 & $2-56$ & 18.3 & $1 / \mathrm{a}$ & 15.11 & 100.0 & $2-39$ & 15.1 & $1 / \mathrm{a}$ & 9.57 & 100.0 & $1-83$ & 9.6 & $1 / \mathrm{a}$ \\
\hline
\end{tabular}

$A$ abundance, $F$ frequency of occurrence, $N$ percentage by number, $W$ percentage by weight, $I R I$ index of relative importance,

$P$ prevalence, $I$ intensity, $m I$ mean intensity, $l$ larva, $a$ adult 


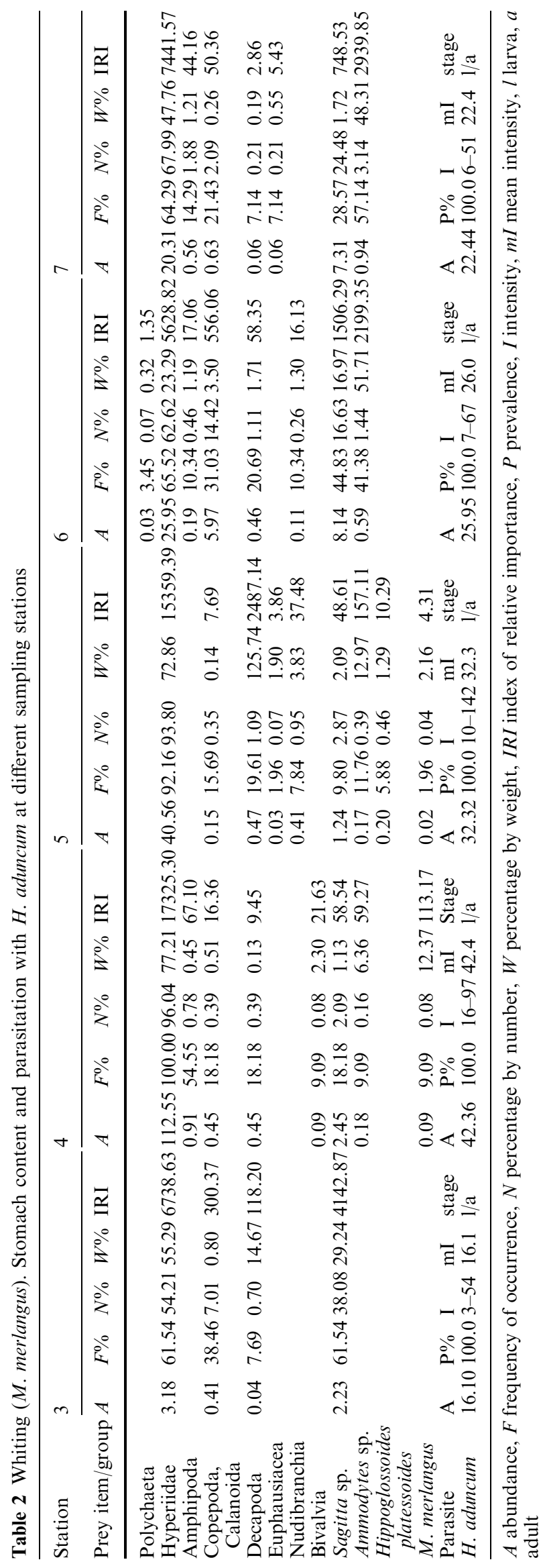

